CARDIOVASCULAR MEDICINE

\title{
Evidence for inequalities in the management of coronary heart disease in Scotland
}

\author{
C R Simpson, P C Hannaford, D Williams
}

Heart 2005;91:630-634. doi: 10.1136/hrt.2004.036723

See end of article for authors' affiliations

....

Correspondence to: Dr Colin Simpson, Department of General Practice \& Primary Care, Foresterhill Health Centre, Westburn Road, The University of Aberdeen, Aberdeen AB25 2AY, UK; c.simp@abdn.ac.uk

Accepted 7 June 2004
Objectives: To investigate whether sex, age, and deprivation inequalities existed in the prescription of secondary preventive treatment for coronary heart disease (CHD) in Scottish general practice and whether these differences altered over time.

Design: 6 year cross sectional study based on general practice morbidity and prescribing data.

Setting: 55 primary care practices in Scotland.

Subjects: 14435 patients with diagnosed CHD.

Main outcome measure: Prescription of various groups of secondary preventive treatment in six study years.

Results: The use of all secondary prevention treatments increased over time $163.6 \%$ of patients with CHD in 1997 to $87.6 \%$ in 2002). After adjustments for age, sex, deprivation, co-morbidities, and practice where appropriate, women received fewer secondary prevention treatments than men, a difference that increased over time (March 1997: adjusted odds ratio (OR) 0.9, 95\% confidence interval (CI) 0.8 to 1.0; March 2002: OR 0.6, 95\% Cl 0.6 to 0.7). Sex differences were observed within each group of treatments studied. The oldest group of patients was less likely than the youngest group to receive any secondary preventive treatment in the year up to March 1997 (OR $0.6,95 \% \mathrm{Cl} 0.5$ to 0.7 ) but were more likely by 2002 (OR 1.3, 95\% Cl 1.1 to 1.5 ) to receive secondary prevention. The most affluent patients with CHD were significantly less likely to receive a statin between March 1998 and 2001 (March 1998 OR 0.6, 95\% $\mathrm{Cl} 0.5$ to 0.9 ), a finding that disappeared by 2002 (OR $0.9,95 \% \mathrm{Cl} 0.7$ to 1.1 ).

Conclusion: The results suggest that inequalities exist in the secondary prevention of CHD in Scotland.

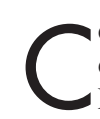
oronary heart disease (CHD) continues to be a leading cause of morbidity and mortality in Scotland, ${ }^{1}$ which has the sixth and fifth highest death rates worldwide for ischaemic heart disease for men and women, respectively. ${ }^{2}$ The white paper "Towards a healthier Scotland" set targets of halving premature mortality from CHD by 2010 and outlined a programme of regular measurements to identify health inequalities. ${ }^{3}$ The 2002 CHD strategy for Scotland recommended that prevention strategies should adopt a population approach to improve the general health status of Scottish communities, complemented by a targeted high risk approach for patients at increased risk of developing CHD. ${ }^{4}$ Such approaches have contributed to a reduction in CHD mortality through a combination of reductions in major risk factors such as smoking and the treatment of cholesterol and blood pressure. ${ }^{5}$ Secondary prevention treatments are based on evidence of the effectiveness of antiplatelet agents (aspirin and clopidogrel), statins, $\beta$ blockers, and angiotensin converting enzyme (ACE) inhibitors in patients with CHD. ${ }^{6}$

Although there have been important decreases in CHD mortality in recent years, Scottish men have benefited from a $10 \%$ greater reduction than women since $1980 .{ }^{1}$ Furthermore, cross sectional studies suggested a lower use of secondary prevention treatments among women than among men. ${ }^{78}$ Meanwhile, studies have also shown temporal increases in the use of aspirin and statins for the secondary prevention of CHD. ${ }^{9-11}$

We investigated whether sex, age, or deprivation inequalities existed in the prescription of secondary prevention treatments for CHD in Scottish general practice and whether these differences altered over the six years studied. In addition, we determined whether age and deprivation differences occurred over this time.

\section{METHODS}

Anonymised data were obtained by the Primary Care Clinical Informatics-Research Unit (PCCIU-R) at the Department of General Practice \& Primary Care, University of Aberdeen, from 55 practices participating in the continuous morbidity recording (CMR) project in Scotland. ${ }^{12}$ Since 1994 the number of practices contributing data has increased such that by 2001, all practices were contributing up to date morbidity data. The practices record detailed information on repeat prescriptions with the reason for every face to face doctor-patient encounter coded and entered by trained data operators. Participating practices are encouraged to record data to their highest level of diagnostic certainty. Diagnoses include events confirmed by hospital colleagues as well as those made within general practice. The Information and Statistics Division administers the CMR project and operates a continuous quality assurance system for completeness and accuracy of data entry. ${ }^{13}$

From the accumulated data, we identified patients registered with the practices and who had a computer record of ever having had a CHD event (indicated by a Read code of G3 and below) on 31 March for six successive years (1997 to 2002). We also determined key characteristics of each identified patient with CHD at each time point: sex, age $(<54,55-64,65-75$, and $\geqslant 75)$, the number of related comorbidities (diabetes ( $\mathrm{Cl} 10$ and below), heart failure (G582 and below), or hypertension (G2 and below)), and deprivation quintiles. Deprivation categories are based on Carstairs's

Abbreviations: $A C E$, angiotensin converting enzyme; $C H D$, coronary heart disease; CMR, continuous morbidity recording; PCCIU-R, Primary Care Clinical Informatics-Research Unit 
Table 1 Age and sex standardised prevalence of CHD among men and women at 31 March of successive years

\begin{tabular}{|c|c|c|c|c|c|c|c|}
\hline \multirow[b]{2}{*}{ Year } & \multirow[b]{2}{*}{$\begin{array}{l}\text { Number of } \\
\text { practices }\end{array}$} & \multicolumn{3}{|l|}{ Men } & \multicolumn{3}{|l|}{ Women } \\
\hline & & Population & CHD cases & $\begin{array}{l}\text { Prevalence (\%) } \\
(95 \% \mathrm{CI})^{*}\end{array}$ & Population & CHD cases & $\begin{array}{l}\text { Prevalence (\%) } \\
(95 \% \mathrm{CI})^{*}\end{array}$ \\
\hline 1997 & 37 & 101371 & 2678 & $2.9(2.8$ to 3.0$)$ & 106826 & 2116 & $1.8(1.7$ to 1.8$)$ \\
\hline 1998 & 40 & 111787 & 3754 & 3.8 (3.7 to 3.9 ) & 117292 & 2983 & 2.3 (2.2 to 2.4 ) \\
\hline 1999 & 48 & 140818 & 5200 & $4.0(3.9$ to 4.1$)$ & 147476 & 4160 & 2.5 (2.4 to 2.5$)$ \\
\hline 2000 & 53 & 169483 & 6175 & 3.8 (3.7 to 3.9$)$ & 176413 & 4919 & 2.3 (2.3 to 2.4$)$ \\
\hline 2001 & 55 & 177296 & 7341 & $4.2(4.1$ to 4.3$)$ & 183085 & 5921 & 2.7 (2.6 to 2.7 ) \\
\hline 2002 & 55 & 178396 & 8002 & 4.5 (4.4 to 4.6$)$ & 183759 & 6433 & 2.9 (2.8 to 2.9$)$ \\
\hline
\end{tabular}

*Directly standardised age and sex adjusted percentages based on the population at 31 March 2002 as the standard population.

$\mathrm{CHD}$, coronary heart disease; $\mathrm{Cl}$, confidence interval.

seven scores, with each quintile representing one fifth of the whole Scottish population. ${ }^{14}{ }^{15}$ The postcode was missing for a small number $(n=200)$ of all patients registered with the study database and those patients were assigned their practice postcode. The deprivation category 1 represents the most affluent group of patients with category 5 representing the most deprived.

Use of secondary prevention treatments was assessed by determining whether at each of the six end of year time points a prescription for an ACE inhibitor, an antiplatelet (including aspirin and clopidogrel), a $\beta$ blocker, and a statin had been issued in the preceding 12 months. The chances of the sex, age, and deprivation groups receiving each type of treatment was determined by calculating the odds ratios and $95 \%$ confidence intervals. The first group within each variable served as the reference group. The odds ratios were adjusted for potential confounding by sex, age, co-morbidity, deprivation, and practice differences by binary logistic regression. For clarity, each odds ratio and 95\% confidence interval was rounded to one decimal point. This sometimes meant that the upper or lower limit of the confidence interval appeared to be the same as the odds ratio. Data were analysed with SPSS for Windows 11.0 (SPSS Inc, Chicago, Illinois, USA). The study protocol was approved by the Scientific Advisory Group of the PCCIU-R.

\section{RESULTS}

At 31 March 2002, 14435 (4.0\%) of all patients registered in our study practices had a code for CHD on their records. During the six study years, the prevalence of CHD had increased with men having higher rates at each time point than women (table 1).

Table 2 Chance (adjusted ORs) of male and female patients with CHD receiving a secondary preventive drug at 31 March of successive years

\begin{tabular}{|c|c|c|c|c|}
\hline \multirow{2}{*}{$\begin{array}{l}\text { Secondary } \\
\text { prevention }\end{array}$} & \multirow[b]{2}{*}{ Year } & \multirow{2}{*}{$\frac{\text { Men }^{*}}{\text { Received treatment }}$} & \multicolumn{2}{|l|}{ Women } \\
\hline & & & Received treatment & Adjusted OR $(95 \% \mathrm{Cl}) \dagger$ \\
\hline \multicolumn{5}{|c|}{ ACE inhibitors } \\
\hline & 1997 & 360 (13.4\%) & 244 (11.5\%) & $0.8(0.7$ to 0.9$)$ \\
\hline & 1998 & $674(18.0 \%)$ & $433(14.5 \%)$ & 0.7 (0.6 to 0.8$)$ \\
\hline & 1999 & $1100(21.2 \%)$ & 731 (17.6\%) & $0.7(0.6$ to 0.8$)$ \\
\hline & 2000 & $1554(25.2 \%)$ & 1028 (20.9\%) & $0.7(0.6$ to 0.8$)$ \\
\hline & 2001 & 2228 (30.4\%) & $1446(24.4 \%)$ & $0.7(0.6$ to 0.7$)$ \\
\hline & 2002 & 2898 (36.2\%) & $1806(28.1 \%)$ & $0.6(0.5$ to 0.6$)$ \\
\hline \multicolumn{5}{|l|}{ Antiplatelets } \\
\hline & 1997 & 925 (34.5\%) & 705 (33.3\%) & $0.9(0.8$ to 1.1$)$ \\
\hline & 1998 & 1906 (50.8\%) & 1440 (48.3\%) & $0.9(0.8$ to 1.0$)$ \\
\hline & 1999 & 3269 (62.9\%) & $2423(58.2 \%)$ & $0.8(0.7$ to 0.9$)$ \\
\hline & 2000 & $4410(71.4 \%)$ & $3267(66.4 \%)$ & 0.7 (0.7 to 0.8$)$ \\
\hline & 2001 & 5207 (70.9\%) & $3982(67.3 \%)$ & 0.8 (0.8 to 0.9$)$ \\
\hline & 2002 & 5788 (72.3\%) & $4518(70.2 \%)$ & 0.8 (0.8 to 0.9$)$ \\
\hline \multicolumn{5}{|l|}{$\beta$ Blockers } \\
\hline & 1997 & $637(23.8 \%)$ & 463 (21.9\%) & $1.0(0.9$ to 1.1$)$ \\
\hline & 1998 & 1251 (33.3\%) & $852(28.6 \%)$ & $0.9(0.8$ to 1.0$)$ \\
\hline & 1999 & $2086(40.1 \%)$ & $1459(35.1 \%)$ & $0.9(0.8$ to 1.0$)$ \\
\hline & 2000 & $2833(45.9 \%)$ & $1966(40.0 \%)$ & $0.9(0.8$ to 1.0$)$ \\
\hline & 2001 & $3576(48.7 \%)$ & $2510(42.4 \%)$ & $0.9(0.8$ to 0.9$)$ \\
\hline & 2002 & $4056(50.7 \%)$ & $2838(44.1 \%)$ & 0.8 (0.8 to 0.9$)$ \\
\hline \multicolumn{5}{|l|}{ Statins } \\
\hline & 1997 & $422(15.8 \%)$ & 244 (11.5\%) & $0.9(0.7$ to 1.1$)$ \\
\hline & 1998 & $951(25.3 \%)$ & $569(19.1 \%)$ & $0.9(0.8$ to 1.0$)$ \\
\hline & 1999 & 1807 (34.8\%) & $1092(26.3 \%)$ & $0.8(0.7$ to 0.9$)$ \\
\hline & 2000 & $2821(45.7 \%)$ & $1762(35.8 \%)$ & $0.8(0.7$ to 0.9$)$ \\
\hline & 2001 & 3407 (46.4\%) & 2178 (36.8\%) & $0.8(0.7$ to 0.8$)$ \\
\hline & 2002 & 4373 (54.6\%) & $2894(45.0 \%)$ & 0.8 (0.7 to 0.8$)$ \\
\hline \multicolumn{5}{|c|}{ At least one secondary preventive treatment } \\
\hline & 1997 & $1792(64.6 \%)$ & $1322(62.5 \%)$ & $0.9(0.8$ to 1.0$)$ \\
\hline & 1998 & 2922 (72.6\%) & $2225(67.5 \%)$ & $0.8(0.7$ to 0.9$)$ \\
\hline & 1999 & $4433(81.7 \%)$ & $3413(75.8 \%)$ & $0.7(0.6$ to 0.8$)$ \\
\hline & 2000 & $5650(86.5 \%)$ & $4323(80.7 \%)$ & $0.6(0.6$ to 0.7$)$ \\
\hline & 2001 & $6641(88.2 \%)$ & $5188(83.4 \%)$ & $0.6(0.6$ to 0.7$)$ \\
\hline & 2002 & $7325(89.4 \%)$ & $5725(85.5 \%)$ & $0.6(0.6$ to 0.7$)$ \\
\hline
\end{tabular}


The use of all secondary prevention treatments increased over the study years (table 2). Overall $63.6 \%$ of patients with CHD received at least one type of treatment in 1997 compared with $87.6 \%$ in 2002. Increases occurred in each treatment group, particularly in the use of antiplatelets and statins. Women were less likely to receive secondary prevention treatments. These sex differences tended to increase over time, especially in the use of any secondary prevention treatment, ACE inhibitors, and $\beta$ blockers. The oldest patients (those aged over 75 years) were significantly less likely than the youngest patients to receive any secondary prevention treatment in the year up to March 1997, a finding that had reversed by 2002 (table 3 ). Older patients were less likely to be prescribed $\beta$ blockers and statins but more likely to receive antiplatelets.

Compared with the most affluent patients with CHD, patients in the lowest deprivation category quintile were significantly less likely to receive a statin between March 1998 and March 2001 (table 4). However, by 2002 this difference had disappeared with no significant difference between the two groups.

\section{DISCUSSION}

This analysis of prescribing data derived from a number of practices in Scotland has shown important differences in the provision of secondary preventive treatments for CHD. Women were less likely than men to receive any one secondary prevention treatment, ACE inhibitors, antiplatelets, $\beta$ blockers, or statins. These differences tended to worsen over the study period. Important differences in prescribing between age groups existed for all secondary preventive treatments. A lower use of statins was found among the most deprived group in the years ending March 1998 through to March 2001.

This study was based on a relatively large dataset derived from practices broadly representative of all Scottish practices apart from those serving very deprived areas. Patients assessed in the study were those with a documented episode of CHD on their computerised record. We did not have details of the criteria used when the diagnosis was made.

Over the six year study period, we observed an increasing prevalence of CHD in contrast to a declining incidence in the rates recorded by national datasets. ${ }^{16}$ The difference may be due to temporal changes in the completeness of recording of CHD by the practices in our dataset, to improved survival, or to changes in diagnostic criteria. Others have found that a programme of repeated assessment, feedback, and training appears to improve data quality. ${ }^{17}$ A notable feature of CMR practices is the dedicated support to enter each patientdoctor contact. Therefore, once a diagnosis is made, there should not be any difference between patients in the recording of that diagnosis. In addition, our outcome measure (drug treatment) is recorded routinely and comprehensively by all practices for all patients. Thus, whatever the diagnostic label applied, appropriate secondary prevention should be the same, irrespective of age, sex, or deprivation. Comparisons between groups and over time, therefore, should be valid.

Table 3 Chance (adjusted OR) of patients of different age groups with CHD receiving different secondary preventive treatments at 31 March of successive years

\begin{tabular}{|c|c|c|c|c|c|c|c|c|}
\hline & \multirow[b]{3}{*}{ Year } & \multicolumn{7}{|c|}{ Age group (years) } \\
\hline & & \multirow{2}{*}{$\begin{array}{l}<55^{\star} \\
\text { Received } \\
\text { treatment }\end{array}$} & \multicolumn{2}{|l|}{$55-64$} & \multicolumn{2}{|l|}{$65-74$} & \multicolumn{2}{|l|}{$\geqslant 75$} \\
\hline & & & $\begin{array}{l}\text { Received } \\
\text { treatment }\end{array}$ & $\begin{array}{l}\text { Adjusted OR } \\
(95 \% \mathrm{Cl}) \dagger\end{array}$ & $\begin{array}{l}\text { Received } \\
\text { treatment }\end{array}$ & $\begin{array}{l}\text { Adjusted OR } \\
(95 \% \mathrm{Cl}) \dagger\end{array}$ & $\begin{array}{l}\text { Received } \\
\text { treatment }\end{array}$ & $\begin{array}{l}\text { Adjusted OR } \\
(95 \% \mathrm{Cl}) \dagger\end{array}$ \\
\hline \multicolumn{9}{|l|}{ ACE inhibitors } \\
\hline & 1997 & $79(11.6 \%)$ & 168 (12.9\%) & 0.9 (0.7 to 1.2$)$ & $210(13.3 \%)$ & $0.9(0.7$ to 1.2$)$ & 147 (12.0\%) & $0.8(0.6$ to 1.1$)$ \\
\hline & 1998 & $143(13.8 \%)$ & 291 (15.8\%) & $0.9(0.8$ to 1.2$)$ & 377 (17.0\%) & $1.0(0.8$ to 1.2$)$ & $296(18.0 \%)$ & $1.1(0.9$ to 1.4$)$ \\
\hline & 1999 & 234 (17.3\%) & 454 (18.3\%) & $0.9(0.7$ to 1.1$)$ & $636(20.5 \%)$ & $0.9(0.8$ to 1.1$)$ & 507 (21.0\%) & 1.0 (0.8 to 1.2$)$ \\
\hline & 2000 & $285(20.1 \%)$ & $595(22.0 \%)$ & $1.0(0.8$ to 1.2$)$ & 898 (24.1\%) & $1.0(0.8$ to 1.1$)$ & 804 (24.8\%) & $1.0(0.8$ to 1.1$)$ \\
\hline & 2001 & $439(26.0 \%)$ & $850(27.0 \%)$ & $0.9(0.8$ to 1.1$)$ & $1303(29.3 \%)$ & $0.9(0.8$ to 1.0$)$ & $1082(27.2 \%)$ & $0.8(0.7$ to 0.9$)$ \\
\hline & 2002 & $541(30.0 \%)$ & $1100(32.6 \%)$ & $1.0(0.9$ to 1.1$)$ & $1636(34.2 \%)$ & $1.0(0.8$ to 1.1$)$ & 1427 (31.9\%) & $0.8(0.7$ to 0.9$)$ \\
\hline \multicolumn{9}{|l|}{ Antiplatelets } \\
\hline & 1997 & 234 (34.3\%) & $426(32.7 \%)$ & $0.9(0.8$ to 1.1$)$ & $584(36.9 \%)$ & $1.2(1.0$ to 1.4$)$ & $386(31.4 \%)$ & $0.9(0.8$ to 1.1$)$ \\
\hline & 1998 & 465 (44.9\%) & 922 (50.1\%) & $1.2(1.1$ to 1.5$)$ & $1176(53.0 \%)$ & 1.5 (1.3 to 1.7$)$ & 783 (47.6\%) & $1.2(1.0$ to 1.4$)$ \\
\hline & 1999 & $685(50.7 \%)$ & $1539(61.9 \%)$ & 1.6 (1.4 to 1.8$)$ & $2013(64.8 \%)$ & $1.9(1.6$ to 2.2$)$ & $1455(60.3 \%)$ & $1.6(1.4$ to 1.9$)$ \\
\hline & 2000 & $796(56.2 \%)$ & $1864(68.8 \%)$ & $1.7(1.5$ to 1.9$)$ & $2774(74.3 \%)$ & $2.2(1.9$ to 2.5$)$ & $2243(69.3 \%)$ & 1.8 (1.5 to 2.0$)$ \\
\hline & 2001 & $956(56.7 \%)$ & $2163(68.6 \%)$ & $1.7(1.5$ to 1.9$)$ & $3326(74.9 \%)$ & 2.3 (2.0 to 2.6 ) & $2744(68.9 \%)$ & $1.7(1.5$ to 1.9$)$ \\
\hline & 2002 & $1057(58.6 \%)$ & $2376(70.4 \%)$ & 1.6 (1.5 to 1.9$)$ & 3652 (76.4\%) & $2.3(2.0$ to 2.6$)$ & $3221(72.0 \%)$ & 1.8 (1.6 to 2.0$)$ \\
\hline \multicolumn{9}{|l|}{$\beta$ Blockers } \\
\hline & 1997 & $201(29.5 \%)$ & $362(27.8 \%)$ & $0.9(0.7$ to 1.1$)$ & $342(21.6 \%)$ & $0.6(0.5$ to 0.8$)$ & 195 (15.9\%) & $0.4(0.3$ to 0.5$)$ \\
\hline & 1998 & $410(39.6 \%)$ & $684(37.2 \%)$ & $0.9(0.8$ to 1.0$)$ & $645(29.1 \%)$ & $0.6(0.5$ to 0.7$)$ & $364(22.1 \%)$ & $0.4(0.3$ to 0.5$)$ \\
\hline & 1999 & 619 (45.8\%) & $1096(44.1 \%)$ & 0.9 (0.8 to 1.0$)$ & 1171 (37.7\%) & $0.7(0.6$ to 0.8$)$ & 659 (27.3\%) & $0.4(0.4$ to 0.5$)$ \\
\hline & 2000 & 727 (51.3\%) & $1346(49.7 \%)$ & $0.9(0.8$ to 1.0$)$ & $1623(43.5 \%)$ & $0.7(0.6$ to 0.8$)$ & $1103(34.1 \%)$ & $0.5(0.4$ to 0.5$)$ \\
\hline & 2001 & $916(54.3 \%)$ & 1641 (52.0\%) & $0.9(0.8$ to 1.0$)$ & $2070(46.6 \%)$ & $0.7(0.6$ to 0.8$)$ & 1459 (36.6\%) & $0.5(0.4$ to 0.5$)$ \\
\hline & 2002 & 988 (54.8\%) & 1835 (54.4\%) & $1.0(0.9$ to 1.1$)$ & 2329 (48.7\%) & $0.7(0.7$ to 0.8$)$ & 1742 (38.9\%) & $0.5(0.4$ to 0.6$)$ \\
\hline \multicolumn{9}{|l|}{ Statins } \\
\hline & 1997 & $152(22.2 \%)$ & $261(20.1 \%)$ & $0.9(0.7$ to 1.1$)$ & $211(13.3 \%)$ & $0.5(0.4$ to 0.6$)$ & $42(3.4 \%)$ & $0.1(0.1$ to 0.2$)$ \\
\hline & 1998 & $358(34.6 \%)$ & $554(30.1 \%)$ & $0.9(0.7$ to 1.1$)$ & $507(22.9 \%)$ & $0.5(0.4$ to 0.6$)$ & $101(6.1 \%)$ & $0.1(0.1$ to 0.1$)$ \\
\hline & 1999 & 571 (42.2\%) & $1030(41.4 \%)$ & $1.0(0.8$ to 1.1$)$ & $1039(33.4 \%)$ & $0.7(0.6$ to 0.7$)$ & 259 (10.7\%) & 0.1 (0.1 to 0.2$)$ \\
\hline & 2000 & 752 (53.1\%) & 1455 (53.7\%) & $1.0(0.9$ to 1.2$)$ & 1818 (48.7\%) & $0.8(0.7$ to 0.9$)$ & $558(17.2 \%)$ & $0.2(0.2$ to 0.2$)$ \\
\hline & 2001 & 881 (52.3\%) & 1699 (53.9\%) & $1.1(0.9$ to 1.2$)$ & 2149 (48.4\%) & $0.8(0.7$ to 0.9$)$ & $856(21.5 \%)$ & $0.2(0.2$ to 0.3$)$ \\
\hline & 2002 & $1013(56.2 \%)$ & 2064 (61.2\%) & $1.2(1.1$ to 1.4$)$ & 2862 (59.1\%) & 1.1 (1.0 to 1.2$)$ & $1364(30.5 \%)$ & $0.3(0.3$ to 0.4$)$ \\
\hline \multicolumn{9}{|c|}{ At least one secondary preventive treatment } \\
\hline & 1997 & $442(64.8 \%)$ & $868(66.7 \%)$ & $1.0(0.8$ to 1.2$)$ & $1031(65.1 \%)$ & $0.9(0.7$ to 1.1$)$ & $710(57.8 \%)$ & $0.6(0.5$ to 0.7$)$ \\
\hline & 1998 & $774(69.6 \%)$ & $1462(74.3 \%)$ & $1.2(1.0$ to 1.5$)$ & $1728(72.1 \%)$ & $1.1(0.9$ to 1.3$)$ & $1183(64.3 \%)$ & $0.7(0.6$ to 0.9$)$ \\
\hline & 1999 & $1054(74.3 \%)$ & $2143(82.2 \%)$ & $1.5(1.3$ to 1.8$)$ & $2691(81.9 \%)$ & $1.5(1.3$ to 1.7$)$ & $1958(74.8 \%)$ & $1.0(0.9$ to 1.2$)$ \\
\hline & 2000 & $1153(77.5 \%)$ & $2465(86.2 \%)$ & $1.7(1.4$ to 2.0$)$ & 3991 (87.5\%) & $1.9(1.6$ to 2.2$)$ & $3394(80.1 \%)$ & $1.1(1.0$ to 1.4$)$ \\
\hline & 2001 & $1347(79.4 \%)$ & $2869(88.4 \%)$ & $1.9(1.6$ to 2.3$)$ & 4089 (89.5\%) & $2.0(1.7$ to 2.4$)$ & 3497 (83.3\%) & $1.2(1.0$ to 1.4$)$ \\
\hline & 2002 & 1488 (80.3\%) & 3461 (89.3\%) & 2.0 (1.7 to 2.3$)$ & 4915 (91.3\%) & $2.4(2.0$ to 2.8$)$ & 4551 (85.5\%) & $1.3(1.1$ to 1.5$)$ \\
\hline
\end{tabular}

*Reference group; tadjusted for sex, practice differences, deprivation, and number of co-morbidities. 


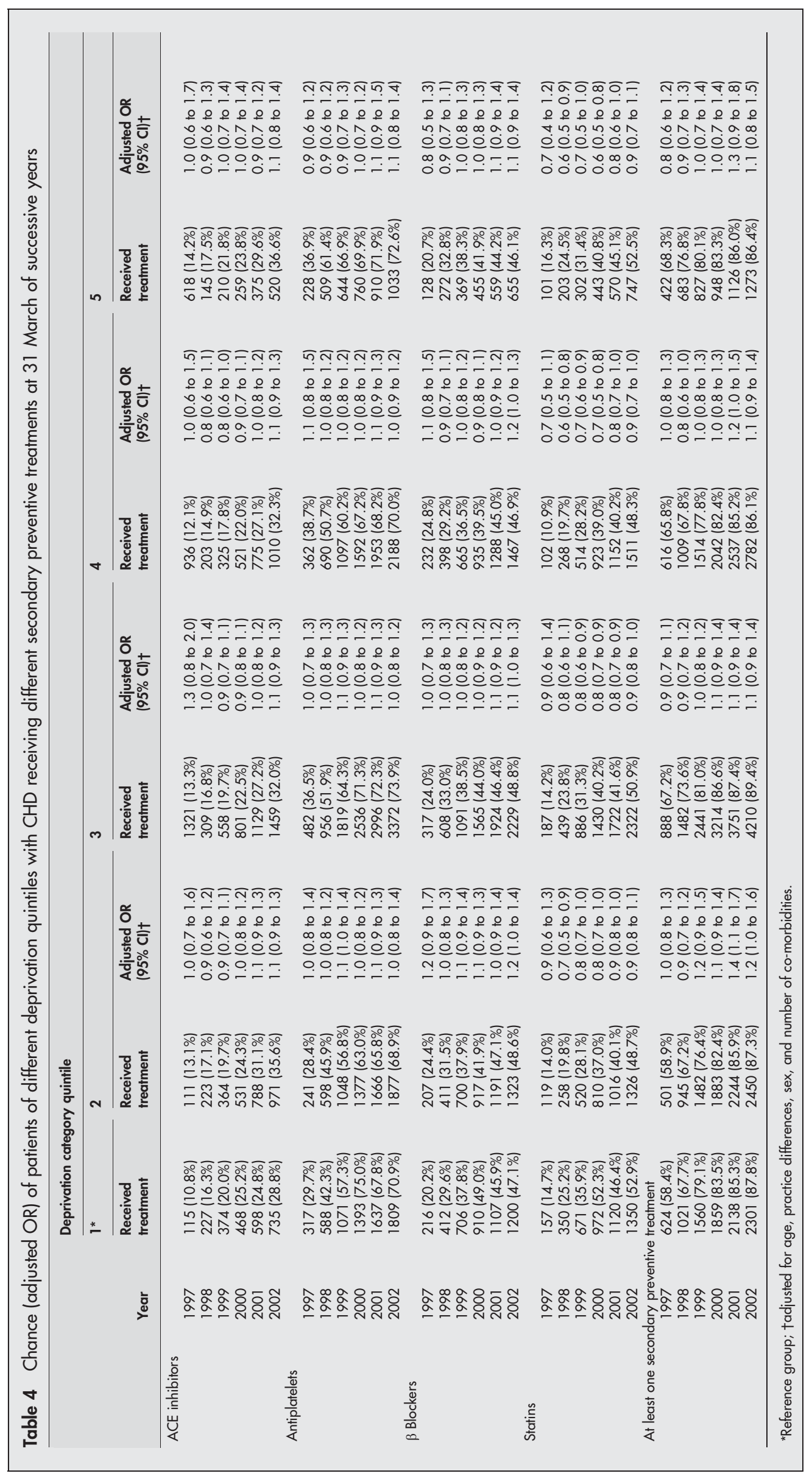


One consequence of having a larger number of patients at risk over the study period was that the odds ratio estimates became more stable, with narrower confidence intervals. Some of the trends over time, therefore, may have been due to increasing precision of the risk estimates. We did not have any information about the severity of CHD in different groups in the study, although we did adjust for a number of related disease co-morbidities. Even though we were able to allow for confounding of sex, age, deprivation, or cardiac related co-morbidities, residual confounding from inadequate adjustment or from other important factors (such as smoking status) may account for our findings.

The CHD prevalence in 2002 of $4.0 \%$ obtained from our data compares with the $5.5 \%$ estimate made by the Scottish health survey. ${ }^{18}$ Similar sex differences in secondary preventive treatment have been found in $\operatorname{some}^{78}$ but not all studies. ${ }^{10}$ Although both sexes benefited from substantial use of secondary preventive treatments overall, the widening gap in prescribing between the sexes may explain (at least in part) the more modest fall in mortality from CHD among women in Scotland during the past two decades. Our finding of lower use of statins among the most deprived group in the years ending March 1998 through to March 2001 supports data from another study of statin prescribing of that period, which found that they were prescribed less in more deprived practices. $^{24}$

Although CHD is a leading cause of death among women, women do not usually list heart disease among the health problems they consider important. ${ }^{20}$ Furthermore, the investigation and management of cardiovascular disease differs between women and men. ${ }^{21}$ Several reasons have been put forward to explain this differential care in women. As chest pain is more often associated with normal epicardial arteries in women than in men, practitioners may believe that angina in women is less likely to be followed by serious cardiovascular events. ${ }^{22}$ This may explain, in part, why practitioners are more likely to attribute anginal symptoms in women to noncardiac causes. ${ }^{20}$ Therefore, practitioners may believe that angina is a benign symptom in women leading to less aggressive secondary preventive measures. Research performed in primary care has shown that doctors' interpretations of patients' symptoms and conversational styles differ for men and women. ${ }^{23}$ Women are also less likely to attend for cardiac rehabilitation after a myocardial infarct, which further reduces the opportunity to implement adequate secondary preventive measures that may not have been initiated in hospital. ${ }^{24}$

The lower use of statins among older patients with CHD may have been due to prescriber perceptions that these treatments are less effective or less cost effective in this group. Recent Scottish Intercollegiate Guidelines Network guidelines state that patients taking lipid lowering medication should not have these drugs stopped because of age. ${ }^{25}$ Furthermore, as older patients are more likely to have more severe disease and be treated medically rather than surgically, they would be expected to benefit from important secondary preventive treatment. Some of the reduced provision may be explained by a higher prevalence of comorbidities among the older group. For example, the lower use of $\beta$ blockers may be potentially explained by a higher prevalence of chronic obstructive airways disease. The greater use of antiplatelet agents among older patients than among the youngest group may be explained by younger patients having to pay charges for general practice prescriptions and therefore purchasing their medication from pharmacies without prescription. ${ }^{26}$ Information about such over the counter purchasing of prescriptions tends not to be recorded routinely by practices.
Work still needs to be done to understand why these important group differences exist. Our results suggest that women and the elderly need to be targeted for secondary prevention to benefit from the CHD strategy for Scotland. ${ }^{4}$

\section{ACKNOWLEDGEMENTS}

The authors thank Dr Bob Milne, the Information and Statistics Division, and Mr Matt Sutton and the PLATFORM project for their helpful contributions. The authors are grateful to the general practitioners who provided practice data to the Primary Care Clinical Informatics-Research Unit.

\section{Authors' affiliations}

C R Simpson, P C Hannaford, Department of General Practice \& Primary Care, Foresterhill Health Centre, The University of Aberdeen, Aberdeen, UK

D Williams, Department of Clinical Pharmacology, Grampian

Universities Trust, Foresterhill, Aberdeen, UK

\section{REFERENCES}

1 General Registrar Office for Scotland. Vital events reference tables 2002. http://www.gro-scotland.gov.uk/grosweb/grosweb.nsf/pages/file8/\$file/ 02+6-4.pdf/ (accessed 2 October 2003).

2 World Health Organization. 1996 world health statistics annual. Geneva: WHO, 2001

3 The Scottish Office Department of Health. Towards a healthier Scotland: a white paper on health. Edinburgh: NHS Scotland, 1999.

4 The Scottish Executive Department of Health. Coronary heart disease and stroke: strategy for Scotland. Edinburgh: NHS Scotland, 2002.

5 Critchley JA, Capewell S, Unal B. Life-years gained from coronary heart disease mortality reduction in Scotland: prevention or treatment? J Clin Epidemiol 2003;56:583-90.

6 Second Joint Task Force of European and other Societies on Coronary Prevention. Prevention of coronary heart disease in clinical practice. Recommendations of the second joint task force of European and other Societies on coronary prevention. Eur Heart J 1998; 19:1434-503.

7 Williams D, Bennett K, Feely J. Evidence for an age and gender bias in the secondary prevention of ischaemic heart disease in primary care. $\mathrm{Br} J \mathrm{Clin}$ Pharmacol 2003;55:604-8.

8 Hippisley-Cox J, Pringle $M$, Crown N, et al. Sex inequalities in ischaemic heart disease in general practice: cross sectional survey. BMJ 2001;322:832.

9 Ryan R, Majeed A. Prevalence of ischaemic heart disease and its management with statins and aspirin in general practice in England and Wales, 1994-8. Health Stat Q 2001;12:34-9.

10 DeWilde S, Carey IM, Bremner SA, et al. Evolution of statin prescribing 19942001: a case of agism but not of sexism? Heart 2003;89:417-21.

11 Chin-Dusting JP, Dart AM. Age and the treatment gap in the use of statins. Lancet 2003;361:1925-6.

12 Milne RM, Taylor MW, Taylor RJ. Audit of populations in general practice: the creation of a national resource for the study of morbidity in Scottish general practice. J Epidemiol Community Health 1998;52(supp 1):20S-4S.

13 Information and Statistics Division. CMR data quality assurance report. Edinburgh: NHS Scotland, 2002.

14 Carstairs V, Morris R. Deprivation and health in Scotland. Aberdeen: Aberdeen University Press, 1991.

15 Mackay D, Sutton $M$. The partiality of primary care intelligence and structure. Glasgow: University of Glasgow, 2003.

16 Heartstats. org. British Heart Foundation Statistics website. Coronary heart disease morbidity in Scotland. http://www.heartstats.org/ datapage. asp?id = 3681 (accessed 9 April 2004).

17 Porcheret $M$, Hughes $R$, Evans $D$, et al. Data quality of general practice electronic health records: the impact of a program of assessments, feedback, and training. J Am Med Inform Assoc 2004;1 1:78-86.

18 The Scottish Executive. The Scottish health survey 1998. Edinburgh: The Stationary Office, 2000.

19 Packham C, Pearson J, Robinson J, et al. Use of statins in general practices, 1996-8: cross sectional study. BMJ 2000;320:1583-4.

20 Wenger NK. Coronary heart disease: an older woman's major health risk. BMJ 1997;315:1085-90.

21 Tobin JN, Wassertheil-Smoller S, Wexler JP, et al. Sex bias in considering coronary bypass surgery. Ann Intern Med 1987; 107:19-25.

22 Wenger NK. Gender, coronary artery disease, and coronary bypass surgery. Ann Intern Med 1990;112:557-8.

23 Hall JA, Irish JT, Roter DL, et al. Gender in medical encounters: an analysis of physician and patient communication in a primary care setting. Health Psychol 1994:13:384-92.

24 Tardivel J. Gender differences in relation to motivation and compliance in cardiac rehabilitation. Nurs Crit Care 1998;3:214-9.

25 Scottish Intercollegiate Guidelines Network. Lipids and the primary prevention of coronary heart disease. Edinburgh: SIGN, 1999.

26 Hopper S, Pierce M. Aspirin after myocardial infarction: the importance of over-the-counter use. Fam Pract 1998;15(supp 1):S10-3. 